\title{
AS MASCULINIDADES EM QUESTÃO: UMA PERSPECTIVA DE CONSTRUÇÃO TEÓRICA
}

\author{
Fernando Bagiotto Botton ${ }^{1}$
}

RESUMO: O presente artigo pretende comentar brevemente sobre a construção dos saberes acerca da masculinidade. Para isso, faz uma revisão bibliográfica e historiográfica que nos permite tratar de algumas das contribuições mais significativas para a construção dos estudos sobre a masculinidade nas ciências sociais. Assim, traçaremos um breve panorama de como esses os estudos sobre o masculino e a masculinidade foram sendo discutidos dentre diversos campos como a psicanálise, a sociologia, a antropologia e, obviamente, a história. Por fim, trata-se de uma sucinta revisão bibliográfica que pretende traçar um "apanhado geral” sobre os estudos acerca da masculinidade, sendo especialmente indicado especialmente para novos pesquisadores ou interessados no assunto.

PALAVRAS-CHAVE: masculinidades, gênero, multiplicidade, historiografia.

Focar a masculinidade enquanto objeto de reflexão teórica, no campo historiográfico nacional, ainda significa uma perspectiva inovadora. A problematização do conceito de masculinidade e suas implicações sócio-históricas foi sistematicamente tangenciada na medida em que se fixou a idéia da existência de uma única masculinidade hegemônica baseada na dominação e no poder inquestionável do "patriarca". Trata-se de uma lacuna historiográfica onde o conceito de masculinidade foi compreendido antes como uma consolidação ou uma permanência natural (o que Bourdieu chamaria de dóxa) do que uma construção de gênero passível de ser problematizada. Os esforços para pôr em discussão essa concepção "despercebida” são recentes no interior das ciências humanas e ainda mais recentes na historiografia nacional, por isso, nessa discussão inicial, o presente estudo vem problematizar a masculinidade no

${ }^{1}$ Integrante do grupo PET História UFPR e discente do curso de História da Universidade Federal do Paraná. 
campo histórico-social, através da busca por uma interpretação da construção das noções de masculinidade(s) especialmente no campo acadêmico, através da revisão bibliográfica em busca da forma em que esses assuntos foram abordados no interior das Ciências Sociais, em especial, na historiografia.

A alternativa que adoto para debater a construção da(s) masculinidade(s) e seus estudos referentes é trabalhar com uma possível aproximação teórico-conceitual entre a História e os outros campos das Ciências Humanas, especialmente Sociologia, Antropologia, Filosofia, Letras e Psicologia. Utilizo essa abordagem dada a observação de que a masculinidade atualmente é um campo de estudos "de todos e de ninguém”, ou seja, as abordagens mais férteis do assunto são realizadas tomando em conta um estudo interdisciplinar, o que simultaneamente torna tais estudos mais complexos e aprofundados.

A masculinidade, desde os estudos evolucionistas século XIX, vem sendo estudada a partir de modelos naturalistas que a interpretam enquanto uma conseqüência biológica da formação humana, ou seja, foi vista como sendo puramente sexual-biológica, delimitada pela posse ou não de um objeto físico, a saber, o pênis. Com isso, foi se institucionalizando através dos discursos técnicocientíficos - tanto na sociedade quanto na academia - a concepção de que a personalidade e as ações sociais dos homens seriam delimitadas por sua aparelhagem física, e que a diferença entre os sexos era fruto de uma estrutura natural inquestionável.

O primeiro campo de estudos a questionar parte dessa concepção naturalista foi a psicanálise: A tese freudiana do Complexo de Édipo foi um mote influente, criou-se a concepção de que a masculinidade é formada de acordo com as relações familiares, especialmente quando a criança deseja sexualmente o progenitor do sexo oposto e percebe o progenitor do mesmo sexo enquanto seu rival, segundo a psicanálise um dos fatores que formariam a masculinidade do menino seria o medo de que o pai proceda a castração como represália por seu desejo pela mãe. O Complexo de 
Édipo só teria final quando o menino "reconhecer seu papel" e ao abrir mão do desejo pela mãe, ganhando acesso ao mundo viril do pai e a todas as outras mulheres. Também Lacan (2008) foi paradigmático na interpretação psicanalítica da masculinidade quando seccionou a interpretação do Complexo de Édipo em três tempos: o primeiro é o relacionamento filho-mãe, o segundo é a entrada do pai na relação e o terceiro configura o declínio do Complexo pela renúncia materna da criança através da identificação com o pai (portador físico e simbólico do falo). Embora essa concepção não concebe como biológica a construção da masculinidade, ainda assim naturaliza e essencializa a distinção dos papéis sexuais através de uma explicação delimitada no jogo das relações familiares. Lacan também propôs a tese de que o falo (por falo não se refere necessariamente o pênis, trata-se de um falo simbólico, não físico) demanda uma carga de legitimidade, afirmando o masculino (captador do falo) sob as demais sexualidades (que abrem mão do falo). Para Lacan, a mulher também é possuidora do falo, mas a partir do momento que trava uma relação sexual com um homem, abre a mãe do seu falo para legitimar o falo do homem que a penetra. É notável a compatibilidade entre as interpretações psicanalíticas de Lacan com os estudos de Peter Fry ${ }^{2}$ quando comenta que imaginário brasileiro categoriza o homem através da "atividade" ou da "passividade" na relação sexual, onde só é legítimo o homem que penetra, independentemente qual corpo (pode inclusive penetrar outro homem e manterá sua masculinidade), já o penetrado perde seu status de "homem". Trata-se de uma hierarquia de dominação e submissão onde um índice de atividade/passividade permeia a construção do ser masculino.

$\mathrm{O}$ historiador Albuquerque Jr. critica a interpretação psicanalítica da masculinidade, uma vez que ela opõe a experiênciade-ser-homem à experiência-de-ser-mulher, reproduzindo uma visão contraposta e binária dos gêneros. Muitos estudos feministas também

${ }^{2}$ FRY, Peter. Pra inglês ver: Identidade e política na cultura brasileira. Rio de Janeiro: Jorje Zahar, 1982. 
lançam críticas a interpretação psicanalítica, especialmente a freudiana, ao passo que se baseia no pressuposto naturalizante de uma família heterossexual, nuclear, monogâmica, legitimando um modelo ocidental e burguês de construção familiar, o que acaba por naturalizar uma norma discriminatória onde os não enquadrados no modelo proposto (por exemplo: homossexuais e poligâmicos) são classificados enquanto anômalos, desviantes da normatização. ${ }^{3}$

A crítica feminista da segunda metade do século $\mathrm{XX}$ foi também a principal delatora da concepção essencialista de sexualidade, levantou-se a compreensão de que os sexos não definem os comportamentos sociais, mas sim os gêneros, que eram construídos e delimitados culturalmente e socialmente (eu adicionaria: também subjetivamente) - de acordo com a clássica frase de Simone de Beauvoir "não se nasce mulher, torna-se mulher". ${ }^{4}$ Isso abriu espaço para que se pensasse na construção social dos gêneros, questionando os papéis sexuais antes vistos como "naturais". Tal diferenciação entre sexo e gênero é de fundamental importância para compreensão da masculinidade, uma vez que também a masculinidade passou a ser compreendida como uma construção social. A partir desse momento nega-se o argumento de que os comportamentos de gêneros se constroem naturalmente, visão defendida pelo discurso técnico-científico, agora percebido como defensor de uma posição político-ideológica.

Karen Giffin aponta que os primeiros estudos feministas recusaram a participação dos homens e dos "mens studies" - pois além de estar se consolidando enquanto um campo delimitado - as feministas consideravam que os homens eram os únicos beneficiados pelo sistema de gênero, assim, não passíveis de serem estudados pela nova abordagem que pretendia dar voz às mulheres. ${ }^{5}$

3 CITELI, Maria Teresa. Fazendo diferenças: teorias sobre gênero, corpo e comportamento. Revista de Estudos Feministas, Florianópolis, v. 9, n. 1, 2001.

${ }^{4}$ BEAUVOIR, S. O segundo sexo. São Paulo: Difusão Européia do Livro, 1970.

${ }^{5}$ GIFFIN, Karen. A inserção dos homens nos estudos de gênero: contribuições de um sujeito histórico. 2005. 
Na história, uma perspectiva semelhante também foi adotada, a exemplo, pela historiadora Michelle Perrot. Sua acertada interpretação - de que o corpo feminino havia sido enclausurado no espaço privado e que a historiografia somente referiu-se ao espaço público - considerava que a história não deu voz às mulheres, pois privilegiava a história dos homens. Porém, sua abordagem da "história dos excluídos" não problematizou a masculinidade justamente por considerar que, enquanto unicamente dominantes, os homens nunca poderiam ser considerados como excluídos. Embora esse veto do feminismo e da história dos excluídos foi uma demanda produtiva e até necessária para aquele contexto, a própria estudiosa Giffin concorda que isso auxiliou na consolidação de uma visão de mundo baseada na oposição entre razão e emoção, objetividade e subjetividade, feminino e masculino. Reproduzindo uma ótica de gênero binária e reducionista. ${ }^{6}$

Os estudos acerca da masculinidade, embora modestos desde as décadas de 50 e 60 , acabaram ganhando relativa proporção na década de 70 e se difundiram especialmente na década de 80 nos países anglo-saxões. Segundo Arilha, já em 1979 somavam 1.300 trabalhos acerca da masculinidade somente no Instituto Tecnológico de Massachusetts. ${ }^{7}$ Desta vez, tais estudos foram aceitos, assumidos e impulsionados por uma ampliação e renovação no campo de abordagem dos estudos feministas. Também foram lançadas algumas teses cunhadas por estudos Gays. Com esses fatores, cresce o numero de homens dedicados à reflexão de sua própria existência. Segundo Giffin - nesse momento - há um sentimento de culpa e arrependimento, onde o homem é auto-avaliado como opressor nas relações de gênero e poder. ${ }^{8}$ A violência entra como uma discussão privilegiada nessa ocasião, uma vez que é entendida como um poder

\footnotetext{
${ }^{6}$ GIFFIN, Karen. Op. cit.

${ }^{7}$ Apud CECCHETTO, Fátima Regina. Violência e estilos de masculinidade. Rio de Janeiro: FGV Editora, 2004.

${ }^{8}$ GIFFIN, Karen. Idem.
} 
coercitivo utilizado pelos homens para construírem suas identidades e reproduzirem sua supremacia dentre os gêneros.

Em sintonia com algumas críticas pós-estruturalistas e pósmodernistas - levantaram-se questionamentos quanto à universalidade desta supremacia masculina declarada, uma vez que se encontraram diversas incompatibilidades entre os modelos de poder masculino e a vivência de inúmeros homens. Além disso, levantaramse teses baseadas em estudos qualitativos - especialmente psicológicos - apontando para um sentimento de fragilidade do homem frente à violência, à frieza e ao sofrimento da construção social da virilidade masculina. Tais alegações, levadas a conseqüências lógicas, permitiram que se defendesse, teoricamente, uma "crise da masculinidade".

Na década de 90, o sociólogo Pierre Bourdieu lança sua tese da "Dominação Masculina”, na qual relaciona a vantagem masculina, nas relações de gênero, não só em relações às forças físicas, mas também às forças simbólicas. ${ }^{9}$ Segundo tal tese, dentro do processo histórico humano se instituiu e se reproduziu determinadas relações de violência simbólica, compartilhadas consciente ou inconscientemente entre dominantes e dominados. Nesse aspecto, as relações entre gêneros são, por ele compreendidas, através do conceito de "trocas simbólicas" onde a mulher passa a ser - dentro das relações sociais - objeto de troca, determinado pelo interesse dos homens, reproduzindo o capital simbólico destes homens e sua dominação masculina.

Opõem-se estudiosos crentes na "crise da masculinidade" e os que acreditam na "dominação masculina". De um lado as pesquisas apontam o homem viril, usuário de violência física ou simbólica consciente ou inconscientemente - para manter seu status de dominante. Do outro lado, as pesquisas apresentam o homem sensível e vitimado pelos degradantes processos e rituais de construção do

${ }^{9}$ BOURDIEU, Pierre. A dominação masculina. Rio de janeiro: Bertrand, 1997. 
ideal viril de masculinidade. Nesse impasse concentraram-se grande parte dos debates - muitos ainda atuais - acerca da masculinidade.

Algumas propostas foram apresentadas para superar essa querela. Estudiosos brasileiros como Pedro Paulo de Oliveira, acreditam que tais oposições devem ser relativizadas de acordo com o estrato social dos homens estudados. Para o autor, nos baixos estratos mantêm-se a visão valorativa dos elementos constitutivos do discurso masculino, diferentemente das crises presentes nos homens das classes médias e altas, freqüentadores de consultórios psicológicos.

A historiografia, especialmente nos anos 90 e na presente década, também buscou meios para a superação das oposições criadas pelos debates acerca da masculinidade e suas relações inter-gênero. Durval Muniz de Albuquerque Jr. buscou compreender a masculinidade a partir de uma perspectiva singular: dentro do processo de formação identitária regionalista da figura do nordestino. $^{10}$ Também Maria Izilda Souza Matos mostra a necessidade histórica de se relativizar a contraposição de "masculinidade dominante" contra "masculinidade vitimada" em seu estudo acerca do homem e o sofrimento de amor a partir do cantor romântico Lupicínio Rodrigues (1996). Para a pesquisadora:

Essa universalização impõe dificuldades de se trabalhar com a masculinidade, que varia de contexto para contexto, sendo, portanto, múltipla, apesar das permanências e hegemonias. Assim, sobrevêm a preocupação em desfazer noções abstratas de "homem” enquanto identidade única, a-histórica e essencialista, para pensar a masculinidade como diversidade no bojo da historicidade de suas inter-relações, rastreando-a como múltipla, mutante e diferenciada no plano das configurações de práticas, prescrições, representações e subjetivações. ${ }^{11}$

${ }^{10}$ ALBUQUERQUE JUNIOR, Durval Muniz. Nordestino: Uma Invenção do Falo. Maceió: Edições Catavento, 2003.

${ }^{11}$ MATOS, Maria Izilda Santos de. Por uma História das Sensibilidades: Em Foco: A Masculinidade. História Questões \& Debates, Curitiba, v. 34, 2001, pp. 45-63. p. 47. 
Diante dessa afirmação podemos delinear uma tendência historiográfica que trata a masculinidade de acordo com a singularidade, a subjetividade e a multiplicidade.

O pesquisador australiano Robert Connell que forneceu as bases para tais constatações historiográficas ao conceituar a masculinidade enquanto "uma configuração de prática em torno da posição dos homens na estrutura das relações de gênero". ${ }^{12}$ Podemos destrinchar o conceito de Connell ao perceber que quando se refere a “configurações práticas” fala de ações reais, e não do que é esperado, imaginado ou estipulado. Quando se refere a "prática" comenta que a ação formadora da masculinidade tem uma racionalidade proposital e um sentido histórico definido. Quando se refere a "posição dos homens" se refere às relações sociais, mas também corporais, não excluindo a carga simbólica e física da corporalidade dos homens na formação da masculinidade. E, finalmente, ao se referir a "estrutura de relações de gênero" utiliza a palavra gênero em sentido amplo, compreendendo economia, estado, família, sexualidade, política, nação, sendo o gênero "sempre uma estrutura contraditória". ${ }^{13}$ Através dessa conceituação o autor chega a conclusão de que não podemos falar em somente uma, mas em diversas masculinidades social-historicamente construídas, sendo uma delas a portadora de um status de "hegemônica" e as demais masculinidades periféricas as concorrentes ou afirmadoras dessa. O estudioso Michael Kimmel tratou de mapear as diversas masculinidades hegemônicas construídas no decorrer da história dos Estados Unidos com isso, comenta que as masculinidades se tornam hegemônicas dentro de um modelo de oposição, na negação da feminilidade, mas também e principalmente dos demais modelos de masculinidades concorrentes, trata-se de uma relação de poder homosocial onde se constrói a hegemonia masculina

12 CONNELL, Robert. Políticas da Masculinidade. Educação e Realidade, Porto Alegre. Vol. 20 (2), 1995. p. 188.

${ }^{13}$ CONNELL, Robert. Idem, p. 189. 
de acordo com a supressão e subalternidade das masculinidades concorrentes. $^{14}$

Cria-se através desse discurso um conceito mais abrangente, pluraliza-se a masculinidade que passa a ser mais bem empregada como: "Masculinidades" no plural, a exemplo do livro de Monica Raisa Schpun. ${ }^{15}$

É importante que sejamos cautelosos ao observarmos que ainda parece cedo demais para tomarmos um campo historiográfico das masculinidades enquanto constituído, pois os estudos ainda são escassos para alcançarmos um debate mais aprofundado, especialmente na historiografia nacional. Também podemos notar certa incomunicabilidade entre as diversas ciências humanas, que há pouco tempo estão iniciando estudos realmente interdisciplinares.

Podemos afirmar - e isso parece unanimidade dentre os historiadores- é que as masculinidades não podem ser estudadas, nem entendidas, por si só. Diversas outras "estruturas" e instituições sociais devem ser levadas em conta nos estudos masculinos, como: etnia, classe social, nacionalidade, geração, temporalidade, territorialidade, dentre diversos outros fatores altamente relevantes que não devem ser suprimidos numa pesquisa histórica. Segundo Connel, para entendermos o gênero, precisamos constantemente ir além do gênero. ${ }^{16}$ Devemos fugir de qualquer acusação binária ou reducionista ao estudar esse assunto tão debatido e ainda despercebido estudando a partir da multiplicidade da existência de diversas masculinidades, isso faz do campo de estudos masculinos um espaço fértil para abordagens históricas e interdisciplinares.

\footnotetext{
${ }^{14}$ KIMMEL, Michael. A produção simultânea de masculinidades hegemônicas e subalternas". Horizontes Antropológicos - Corpo, Doença e Saúde. Porto Alegre. Programa de Pós-Graduação em Antropologia Social da UFRGS, n. 9, pp. 103-117, 1998.

${ }^{15}$ SCHPUN, Mônica Raisa (Org.). Masculinidades. São Paulo: Boitempo, 2004. ${ }^{16}$ CONNELL, Robert. Políticas da Masculinidade. Educação e Realidade, Porto Alegre. Vol. 20 (2), 1995.
} 


\section{BIBLIOGRAFIA}

ALBUQUERQUE JUNIOR, Durval Muniz. Nordestino: Uma Invenção do Falo. Maceió: Edições Catavento, 2003.

BEAUVOIR, S. O segundo sexo. São Paulo: Difusão Européia do Livro, 1970.

BOURDIEU, Pierre. A dominação masculina. Rio de janeiro: Bertrand, 1997.

CECCARELLI, Paulo Roberto. A Construção da Masculinidade. Percurso, São Paulo, Vol. 19, pp. 49-56, 1998 Disponível em: http://www.ceccarelli.psc.br/artigos/portugues/html/aconstrucao.htm

(Acesso em: 29 de Agosto de 2008).

- A masculinidade e seus avatares. Catharsis, São Paulo, ano IV, n. 19, 1998. Disponível em: http://www.ceccarelli.psc.br/artigos/portugues/html/amasculinidade.htm (Acesso em: 29 Ago 2008).

CECCHETTO, Fátima Regina. Violência e estilos de masculinidade. Rio de Janeiro: FGV Editora, 2004.

CITELI, Maria Teresa. Fazendo diferenças: teorias sobre gênero, corpo e comportamento. Revista de Estudos Feministas, Florianópolis, v. 9, n. 1, 2001 . Disponível em: http://www.scielo.br/scielo.php?script=sci_arttext\&pid=S0104-

026X2001000100007. (Acesso em: 29 de Agosto de 2008)

CONNELL, Robert. Políticas da Masculinidade. Educação $e$ Realidade, Porto Alegre. Vol. 20 (2), 1995.

FÁVERI, Marlene de. Guerra e papéis masculinos: Reflexões na perspectiva de gênero. Disponível em: http://www.anpuh.uepg.br/xxiiisimposio/anais/textos/MARLENE\%20DE\%20F\%C3\%81VERI.pdf (Acesso em: 29 de Agosto de 2008).

FRY, Peter. Pra inglês ver: Identidade e política na cultura brasileira. Rio de Janeiro: Jorje Zahar, 1982.

GIFFIN, Karen. A inserção dos homens nos estudos de gênero: contribuições de um sujeito histórico. 2005. Disponível em: 
http://redalyc.uaemex.mx/redalyc/pdf/630/63010111.pdf (Acesso em 07 de novembro de 2008).

KIMMEL, Michael. A produção simultânea de masculinidades hegemônicas e subalternas". Horizontes Antropológicos - Corpo, Doença e Saúde. Porto Alegre. Programa de Pós-Graduação em Antropologia Social da UFRGS, n. 9, pp. 103-117, 1998.

LACAN, Jacques, “A Significação do falo” In: Escritos, Rio de Janeiro: Jorge Zahar, 1998.

LEAL, Antonio Segundo Boscán. Propuestas Críticas para uma concepción tradicional de La masculinidad. Opción, Venezuela, vol.

22, n. 051, pp. 26-49. Disponível em: http://redalyc.uaemex.mx/redalyc/src/inicio/ArtPdfRed.jsp?iCve=31022003 (Acesso em: 29 de Agosto de 2008).

MENA, Daniel Cazés. El Tiempo en Masculino. El Cotidiano. Mexico, vol 18, $\mathrm{N}^{\circ} 113$ 2002, pp. 58-70 Disponível em: http://redalyc.uaemex.mx/redalyc/src/inicio/ArtPdfRed.jsp?iCve=32511307

(Acesso em: 29 de Agosto de 2008).

MALUF, Mariana; MOTT, Maria Lúcia. Recônditos do Feminino. In: SEVECENKO, Nicolau (Org.). História da Vida Privada no Brasil. São Paulo: Companhia das Letras, 2006. Vol. 3.

MATOS, Maria Izilda Santos de. Por uma História das Sensibilidades: Em Foco: A Masculinidade. História Questões \& Debates, Curitiba, v. 34, 2001, pp. 45-63.

MATOS, Maria Izilda Santos de; FARIA, Fernando Antonio. Melodia e Sintonia em Lupicínio Rodrigues: O Feminino, O Masculino e Suas Relações. Rio de Janeiro: Bertrand Brasil, 1996. MISKOLCI, Richard. Corpos elétricos: Do ajustamento à estética da existência. Revista de Estudos Feministas, ano/vol. 14, n. 003, 2006, pp. 681-693. Em: http://redalyc.uaemex.mx/redalyc/src/inicio/ArtPdfRed.jsp?iCve=38114306 (Acesso em: 29 de Agosto de 2008) OLIVEIRA, Pedro Paulo de. A construção social da masculinidade. Belo Horizonte: Editora UFMG; Rio de Janeiro: IUPERJ, 2004.

PEDRO, Joana Maria. As guerras na transformação das relações de gênero: entrevista com Luc Capdevila. Revista de Estudos 
Feministas, ano/vol. 13, n. 001, 2005, pp. 81-120 Disponível em: http://redalyc.uaemex.mx/redalyc/src/inicio/ArtPdfRed.jsp?iCve=38113106 (Acesso em: 29 de Agosto de 2008).

PERROT, Michele. Mulheres Públicas. São Paulo: Fundação Editora da UNESP, 1998.

ROJAS, Fernando Huerta. La Deportivización Del Cuerpo Masculino. El Cotidiano. Mexico, vol 18, n. 113 2002, pp. 47-57 Disponível

em: http://redalyc.uaemex.mx/redalyc/src/inicio/ArtPdfRed.jsp?iCve=32511306

(Acesso em: 29 de Agosto de 2008).

SCOTT, Joan. Gênero: uma categoria útil de análise histórica. Educação e Realidade, Porto Alegre, 16, pp. 5-22, jul/dez. 1990.

SCHPUN, Mônica Raisa (Org.). Masculinidades. São Paulo: Boitempo, 2004.

STENGEL, Márcia. Perspectiva psicanalítica da identidade de gênero: Limites e Possibilidades. Interações, ano/vol. 4, n. 12, pp 117-135.

Disponível em: http://redalyc.uaemex.mx/redalyc/src/inicio/ArtPdfRed.jsp?iCve=35461207 (Acesso em: 29 de Agosto de 2008).

WELZER-LANG, Daniel. A construção do masculino: Dominação das mulheres e homofobia. Tradução de Miriam Pillar Grossi. Revista de Estudos Feministas, ano/vol 9, n. 002, 2001 pp. 460-482. Disponível em: http://redalyc.uaemex.mx/redalyc/pdf/381/38109208.pdf (Acesso em: 29 de Agosto de 2008).

VOJNIAC, Fernando. Resenha de: Nordestino: Uma Invenção do Falo. Revista de Estudos Feministas, ano/vol. 11. n. 002, 2003 pp. 664-667. Disponível em: http://redalyc.uaemex.mx/redalyc/src/inicio/ArtPdfRed.jsp?iCve=38111226 (Acesso em: 29 de Agosto de 2008). 